\title{
Patologia em pavimentos flexíveis: estudo de caso para o estacionamento do ITPAC Porto
}

As rodovias são importantes instrumentos para o transporte e desenvolvido do país, entretanto muitas se encontram sem pavimento ou mal conservadas. Em rodovias sem conservação, é comum o aparecimento de patologias, como trincas, afundamentos, ondulações, exsudação, desgaste e remendos. Uma investigação, dessas patologias, foi realizada para uma possível restauração no pavimento do estacionamento do Instituto Tocantinense Presidente Antônio Carlos em Porto Nacional - TO, onde há a prevalência de desgaste e reparos mal executados. Os reparos no pavimento flexível foram feitos com concreto, havendo o surgimento de novas anomalias, como trincas e panelas, devido à falta de aderência entre os diferentes materiais. Observou-se a presença de outras patologias, entretanto, não tanto quanto o desgaste e remendos. Sugere-se que haja uma restauração do pavimento de todo o estacionamento, ou pelo menos na parte mais afetada, já que existe uma parte à qual, por pouca utilização, quase, não há patologias, devendo ser retirado os reparos de concreto antigos e novos deverão ser feitos, de maneira correta.

Palavras-chave: Pavimento Flexível; Patologia; Recuperação de Pavimentos.

\section{Pathology in flexible floors: case study for ITPAC Porto parking}

The highways are important instruments for transportation and developed in the country, however many are unpaved or poorly maintained. On roads without conservation, it is common the appearance of pathologies, like cracks, sinkings, undulations, exudation, wear and patches. An investigation of these pathologies was carried out for a possible restoration on the floor of the parking lot of the Tocantinense Presidente Antônio Carlos Institute in Porto Nacional - TO, where there is a prevalence of poorly executed wear and tear. The repairs to the flexible floor were made with concrete, with the appearance of new anomalies, such as cracks and pans, due to the lack of adhesion between the different materials. It was observed the presence of other pathologies, however, not as much as the wear and patches. It is suggested that there be a restoration of the floor of the whole parking lot, or at least in the most affected part, since there is a part to which, due to little use, there are almost no pathologies, old and new concrete repairs must be removed should be done correctly.

Keywords: Flexible Floor; Pathology; Recovery of Pavements.

Topic: Engenharia Civil

Reviewed anonymously in the process of blind peer.
Received: 17/11/2018

Approved: 05/02/2019
Matheus Lucas Brito Gomes

Instituto Tocantinense Presidente Antônio Carlos, Brasil http://lattes.cnpq.br/1626835484241835

matheus mlbg@hotmail.com

Flávio Vieira da Silva Júnior

Instituto Tocantinense Presidente Antônio Carlos, Brasil

http://lattes.cnpq.br/2211436659738090

flaviovisiju@gmail.com

\section{Referencing this:}

GOMES, M. L. B.; SILVA JÚNIOR, F. V.. Patologia em pavimentos flexíveis: estudo de caso para o estacionamento do ITPAC Porto. Inventionis, v.1, n.1, p.1-11, 2019. DOI:

http://doi.org/10.6008/CBPC2674-6395.2019.001.0001 


\section{INTRODUÇÃO}

As rodovias brasileiras possuem grande importância para o país, por serem instrumento do principal modal de transporte utilizado, o rodoviário, que segundo a Confederação Nacional de Transporte - CNT (2018), mais de $60 \%$ dos transportes brasileiros são feitos por meio de rodovias. A importância é tão significativa que de acordo com o Instituto Brasileiro de Geografia e Estatística - IBGE (2014), através da Pesquisa Anual de Serviços, somente em 2014 o modal rodoviário representou uma responsabilidade de 55,2\% do Produto Interno Bruto (PIB) do setor de transportes no Brasil, contribuindo grandemente para a economia do país. Entretanto, para que os transportes sejam feitos da melhor forma, as estradas precisam ser pavimentadas.

O pavimento é definido como uma estrutura de muitas camadas sobrepostas, com materiais e granulometrias diversas, devendo resistir os esforços a que for exposto, melhorar as condições de segurança e proporcionar conforto aos usuários (BALBO, 2007).

Apesar da importância da pavimentação e da utilização do modal rodoviário, as rodovias brasileiras possuem características que dificultam o transporte, devido à falta de conforto, onde, segundo a CNT (2018), somente cerca de $12,4 \%$ de todas as rodovias do país são pavimentadas, sendo que em torno de $61,8 \%$ possuem algum problema, que as classificam como regular, ruim ou péssima.

Segundo o Departamento Nacional de Infraestrutura de Transportes - DNIT (2018), há 57,2 mil quilômetros de rodovias federais pavimentadas no país sob a sua administração, e apenas 59\%, deste total, se encontra em bom estado de conservação, restando mais de $40 \%$ de rodovias não conservadas. Entretanto, o número é ainda maior quando se fala de todas as rodovias do país, incluindo as estradas estaduais e municipais, onde Araújo et al (2016) afirma que cerca de 80,3\% das estradas do país não são pavimentadas.

Dentre as rodovias pavimentadas no Brasil, Araújo et al (2016) afirma que os tipos de pavimentos mais utilizados são o rígido, com a utilização de concreto, e o flexível, com a utilização de asfalto, e principalmente o pavimento asfáltico flexível, presente em cerca de $95 \%$ das estradas pavimentadas do país. O pavimento flexível é constituído por um revestimento asfáltico disposto sobre uma camada de base de solo, e deve resistir e transmitir os esforços as camadas inferiores (BALBO, 2007).

Segundo Marques (2014), diante da reduzida extensão da malha rodoviária do país, constituída principalmente por pavimentos flexíveis, além da falta de manutenção, há o acometimento de diversas patologias na superfície. De acordo com o DNIT (2009), as patologias existentes nos pavimentos flexíveis podem ser classificadas como:

(A) Fenda: Fissura - fenda no revestimento que não causa problemas funcionais, pouco perceptível a vista desarmada; Trinca transversal - fenda no revestimento facilmente visível, apresentada na direção ortogonal ao eixo da via; Trinca longitudinal - fenda no revestimento facilmente visível, apresentada na direção paralela ao eixo da via; Trinca de retração - fenda no revestimento causada pela retração térmica; Trinca tipo 'Couro de Jacaré' - diversas trincas interligadas, semelhantes ao aspecto do couro de jacaré; - Trinca tipo 'Bloco' - diversas trincas interligadas formando blocos bem definidos;

(B) Afundamento: Afundamento plástico - afundamento causado pela plasticidade de alguma camada do pavimento; Afundamento de consolidação - afundamento causado pela consolidação de alguma camada do pavimento; 
(C) Ondulação: deformação com ondulações ou corrugações transversais dispostos na superfície do pavimento;

(D) Escorregamento: aparecimento de fendas no formato de meia-lua a partir do deslocamento do pavimento;

(E) Exsudação: excesso de ligante betuminoso na superfície do pavimento;

(F) Desgaste: arrancamento progressivo do agregado do pavimento;

(G) Panela ou buraco: cavidade no revestimento;

(H) Remendo: preenchimento de panela;

(I) Remendo profundo: substituição do pavimento e das camadas inferiores de forma retangular;

(J) Remendo superficial: aplicação de camada betuminosa para correção.

Devido a situação da malha rodoviária pavimentada brasileira, com má conservação, cabe conhecer o tipo de patologia existente e fazer a recuperação para esses casos, especialmente as anomalias no revestimento, visto que, segundo Colares (2011), é mais barato fazer a recuperação de rodovias, enquanto possuem condições para isso, pois os danos podem aumentar e ir além do revestimento, atingindo a estrutura e ficando mais caro a recuperação.

Diante do exposto, o presente artigo expõe a investigação das patologias existentes na pavimentação do estacionamento do Instituto Tocantinense Presidente Antônio Carlos - ITPAC Porto, em Porto Nacional/TO, por se tratar de um local que abrange cerca de 2.000 alunos, além da comunidade portuense, encontra-se muitas patologias, algo que diminui o conforto dos usuários. A partir da investigação das patologias, foram descritas as possíveis causas e posteriormente as técnicas de recuperação para o pavimento.

\section{METODOLOGIA}

\section{Tipo De Pesquisa}

Trata-se de um estudo de caso, caracterizado como uma pesquisa aplicada e descritiva com abordagem qualitativa. Segundo Prodanov et al. (2013), o estudo de caso é um tipo de pesquisa aprofundada nas características de determinado assunto, onde se coleta e analisa as informações para estudar todos os aspectos referentes ao assunto da pesquisa, promovendo um detalhado conhecimento.

Já a pesquisa aplicada, Prodanov et al. (2013) afirmam que ela visa gerar conhecimentos para a encontrar soluções ao problema investigado, e a descritiva é aquela onde há o registro e descrição das informações. A abordagem qualitativa, segundo Zanella (2013), é a pesquisa que trabalha com informações expressas em palavras, fotografias etc., para um aprofundamento do pesquisado, não havendo a expressão numérica.

\section{Coleta De Dados}

Os dados foram coletados no estacionamento do Instituto Tocantinense Presidente Antônio Carlos, no período a partir de setembro de 2018 , onde foi identificado algumas patologias para a inclusão no projeto 
de pesquisa. Porém, a coleta de dados para a pesquisa foi feita somente na primeira quinzena do mês de março de 2019, no entanto, após esse período, a partir da utilização do estacionamento, verificou-se que novas patologias haviam surgido, devido à falta de manutenção e reparo, onde novos dados foram coletados na primeira quinzena do mês de abril de 2019.

Para uma melhor observação, de cada patologia presente no pavimento, foi feito um vídeo de toda a extensão do estacionamento, para que os detalhes pudessem ser olhados com paciência e analisados para fazer um mapeamento de patologias. Também foi feito um levantamento fotográfico para mostrar os pontos críticos.

O levantamento foi feito na parte da tarde, devido a exposição da luz solar promover uma melhor visualização das patologias, tanto pessoalmente, quanto por vídeos e fotos. Não houve uma realização de ensaios laboratoriais, visto que se objetivou o levantamento visual. Além disso, foi realizado uma avaliação subjetiva da superfície do pavimento flexível, através das orientações da Norma DNIT 009/2003 - PRO, com a verificação do Valor da Serventia Atual - VSA. Onde a norma determina que deve ser feito com trechos de aproximadamente 600 metros, entretanto o estacionamento possui menos de $400 \mathrm{~m}$, e como foi verificado que as patologias concentram-se na primeira parte do estacionamento, até a divisão das duas partes, a avaliação contou com a verificação das 3 vias do estacionamento, na primeira parte com cerca de 280 metros, conforme a figura 1, onde os trecho são identificados por 1, 2 e 3, dentro do retângulo verde.

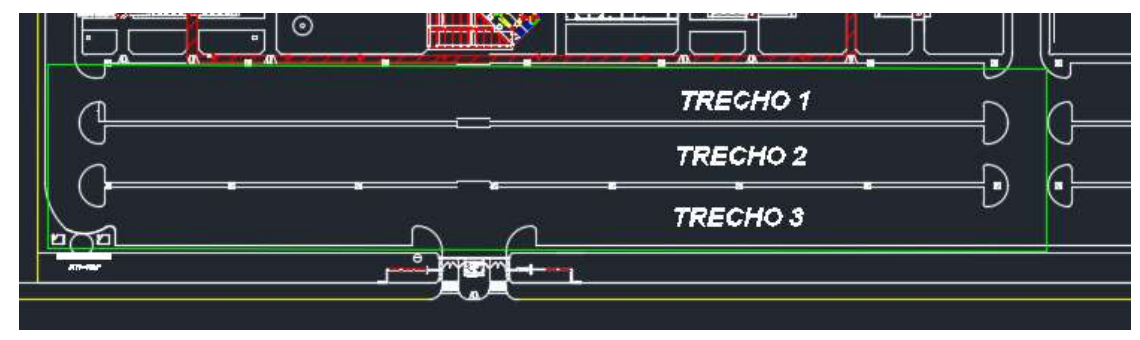

Figura 1: Trecho para avaliação subjetiva da superfície do pavimento.

Coletou-se a partir das opiniões de 5 estudantes do 9 e 10 período de Engenharia Civil, por se tratar de pessoas que possuem conhecimento prévio sobre pavimentação. Os estudantes não foram identificados, por questões éticas, para preservação de identidade. As respostas foram transcritas respeitando fielmente àquilo que avaliaram a partir da ficha de avaliação de serventia.

\section{Análise De Dados}

Para fazer a avaliação subjetiva da superfície do pavimento flexível, foi coletado o resultado da opinião dos 5 estudantes, que responderam a ficha de avaliação de serventia, que há a classificação do estado do pavimento conforme a Tabela 1. Após a avaliação do VSA, foi aplicado a seguinte fórmula, proposta pela Norma DNIT 009/2003 - PRO, funcionando como uma média para avaliar o estado do pavimento:

$$
\begin{array}{r}
\text { VSA }=\frac{\Sigma x}{n} \\
\text { Onde: }
\end{array}
$$

VSA - Valor de Serventia Atual

$X$ - Valores de Serventia Atuai individuais atribuídos por cada membro do grupo $\mathrm{n}$ - número de membros do grupo de avaliação. 
Tabela 1: Nível de serventia do pavimento.

PADRÃO DE CONFORTO AO ROLAMENTO

\title{
EXCELENTE
}

BOM

REGULAR

RUIM

PÉSSIMO

\author{
AVALIAÇÃO (FAIXA DE NOTAS) \\ 4 a 5 \\ 3 a 4 \\ 2 a 3 \\ 1 a 2 \\ 0 a 1
}

Para analisar as patologias presentes no pavimento, descrever as possíveis causas e propor uma solução para a problemática, primeiramente foi feito um mapeamento das patologias, por meio do programa AutoCad 2016, onde a planta baixa do estacionamento foi cedida pela própria instituição. Para a identificação do tipo de patologia, das prováveis causas e bem como das causas, a partir da observação delas, utilizou-se o Manual de Restauração de Pavimentos Asfálticos do DNIT, publicado em 2006.

\section{RESULTADOS E DISCUSSÃO}

Foi verificado que a maior ocupação do estacionamento é em pouco mais da metade dele, a outra parte somente é ocupada esporadicamente, e, dessa forma, quase não houve patologias identificadas. Portanto, as patologias aparecem especialmente pela utilização constante do pavimento. A avaliação subjetiva da superfície do pavimento flexível, realizada nessa parte do estacionamento, obteve as seguintes avaliações dos 5 usuários, descritas na Tabela 2.

Tabela 2: Avaliações dos usuários por trecho.

\begin{tabular}{|c|c|c|c|}
\hline & TRECHO 1 & TRECHO 2 & TRECHO 3 \\
\hline USUÁRIO 1 & 2,3 & 2,1 & 2,9 \\
\hline USÚARIO 2 & 2,5 & 2,5 & 3,1 \\
\hline USUÁRIO 3 & 2,9 & 2,8 & 2,2 \\
\hline USUÁRIO 4 & 2,5 & 2,4 & 3,4 \\
\hline USUÁRIO 5 & 3,1 & 2,9 & 15,4 \\
\hline TOTAL & 13,3 & 12,7 & \\
\hline
\end{tabular}

A partir disso, e aplicando a fórmula, obtêm-se os seguintes resultados para cada trecho: Trecho 1: $\mathrm{VSA}=13,3 / 5=2,66 ;$ Trecho $2: \mathrm{VSA}=12,7 / 5=2,54$; e Trecho 3: VSA=15,4/5 = 3,08. Desse modo, o Trecho 1 é avaliado como regular, o Trecho 2 também como regular, e o Trecho 3 como bom. De um modo geral, todo o estacionamento, considerando a parte pesquisada, é avaliado como regular.

Já no que se refere às patologias, dentro as principais observadas, há um destaque para o desgaste e o remendo. Também há a presença de trincas horizontais, trincas verticais, trincas tipo couro de jacaré e panelas, entretanto há uma predominância muito grande do desgaste e de remendo.

Segundo o DNIT (2006), os remendos são considerados patologias a partir do momento que provocam desconforto. Os remendos observados no ITPAC são do tipo corretivos, que segundo Arteris (2015) são aplicados quando há uma anomalia para reparar, com áreas de até $10 \mathrm{~m}^{2}$. Uma característica observada nos remendos é que apesar do pavimento ser flexível, com o uso de revestimento asfáltico, os remendos em sua totalidade foram feitos com concreto.

Existem remendos em todos os lugares do pavimento, nas 3 vias existentes. Além disso, há uma parte do pavimento, localizado na saída da instituição, que possui uma grande faixa com remendo de concreto, 
sendo que já quase na guarita o pavimento é praticamente todo um reparo de concreto, conforme a Figura 2, contrariando o tamanho de $10 \mathrm{~m}^{2}$ que devem ser requisitos para o reparo corretivo. Para faixas maiores, Arteris (2015) afirma que o reparo é profundo, utilizado quando se deseja reparar até mesmo as camadas inferiores ao revestimento. Este não é o caso dos reparos do ITPAC, onde não foram feitos, incluindo as camadas inferiores ao revestimento.

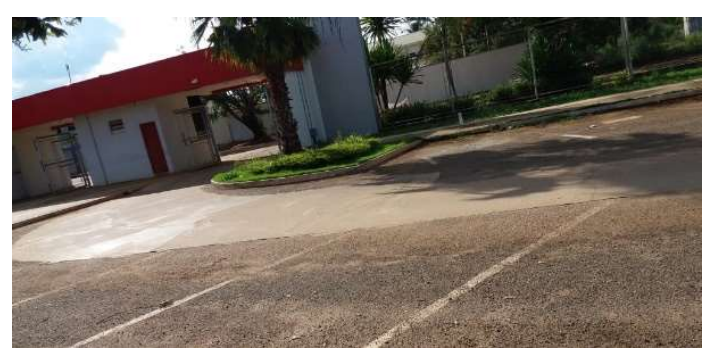

Figura 2 - Enorme faixa de reparo com concreto próximo a guarita do ITPAC.

Segundo Arteris (2016) os remendos corretivos devem ser executados com a utilização de uma mistura asfáltica e seguir diversos procedimentos. Portanto, a aplicação de concreto para reparar patologias de pavimentos flexíveis é inadequada, sendo essa execução no estacionamento do ITPAC é equivocada, devendo ser refeita da maneira correta, através da retirada do concreto e utilização de asfalto.

Normalmente os remendos feitos em pavimentos flexíveis possuem diversas patologias, conforme o DNIT (2006), onde podem apresentar elevações ou abaulamento. O remendo feito no ITPAC, por ser de concreto não apresenta esse tipo de disfunção, é liso e plano. Entretanto, por ser de material diferente do pavimento, no encontro do pavimento asfáltico e o concreto do remendo há uma dificuldade de aderência, surgindo fissuras e desgaste que progridem para o aparecimento de panelas. Isso foi verificado conforme a Figura 3.

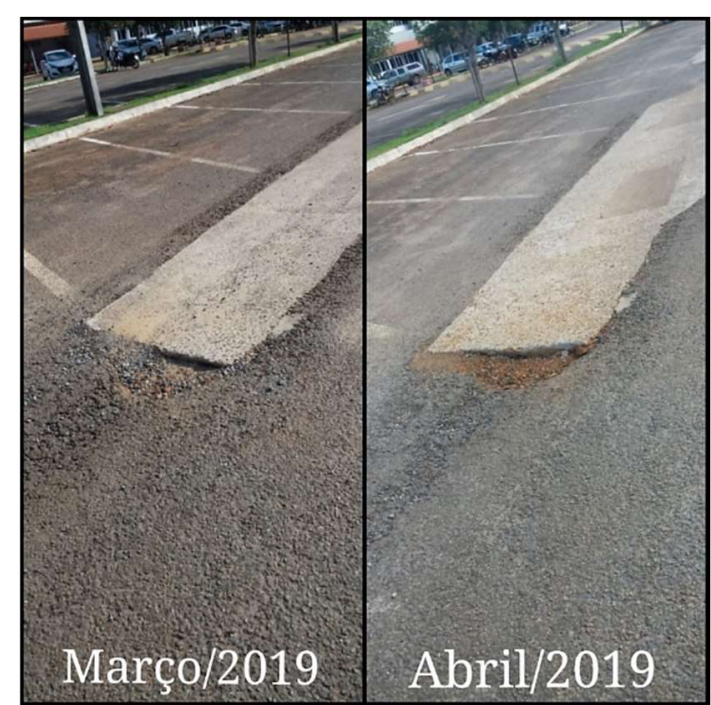

Figura 3: Comparativo de patologia para os meses de março e abril de 2019.

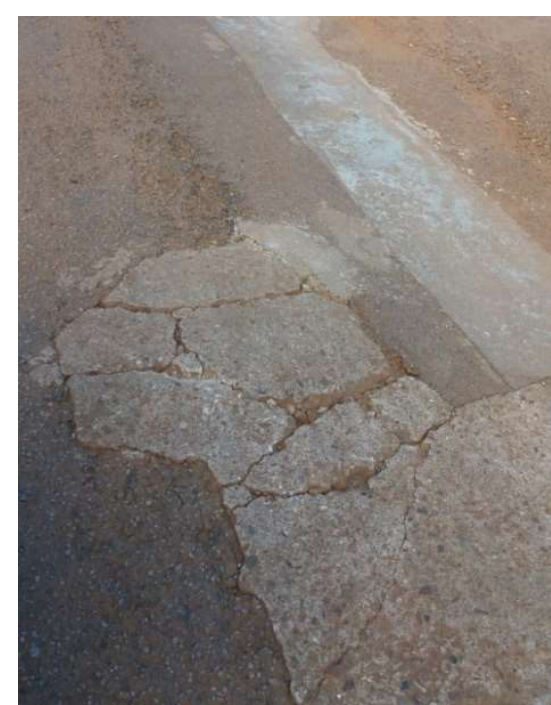

Figura 4: Quebra do concreto do remendo, assemelhando as trincas tipo couro de jacaré.

Percebe-se que em março de 2019 havia fissuras e um desgaste entre o reparo e o pavimento, de tal modo que havia muito material do pavimento flexível arrancado em volta, já em abril de 2019 esse desgaste 
progrediu para uma panela. Isso se dá pelo constante uso e falta de reparo de um mês para o outro, bem como devido ao período chuvoso, onde a água infiltra por meio do desgaste. Isso se dá principalmente devido à aderência deficiente entre o remendo e o pavimento, devendo, dessa forma, ser refeito da maneira correta.

Além disso, há a verificações de remendo com fissura muito semelhante ao tipo couro de jacaré, sendo que esta é causada pela quebra do concreto do remendo, que não suporta o esforço aplicado nele, conforme a figura 4.

Segundo Araújo et al (2016), os pavimentos de concreto são chamados de pavimentos rígidos, e há uma menor distribuição dos esforços para as camadas inferiores, diferente do pavimento flexível. Por isso os remendos de concreto, semelhantes ao pavimento de concreto, tem a possibilidade de quebrar.

As trincas verificadas ao longo do pavimento flexível, exceto as das faixas, estão presentes, especialmente devido aos remendos. Há trincas em todas as laterais dos remendos, conforme é visto na Figura 5, as maiores são localizadas nos remendos, devido a passagem de tubulações no pavimento.

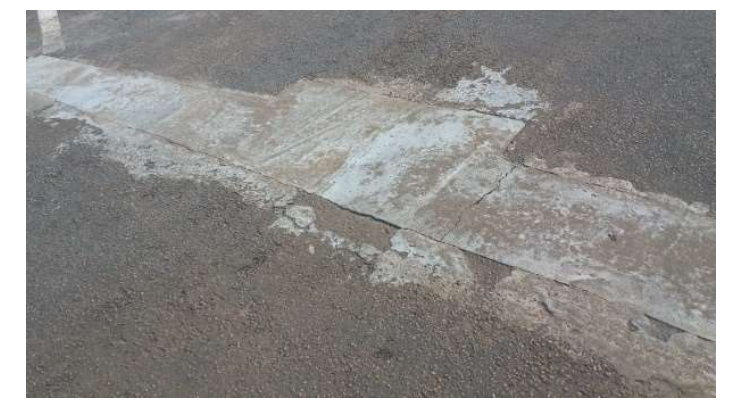

Figura 5: Grande fissura no encontro do pavimento flexível e do remendo.

Um outro caso que cabe ressaltar com a utilização de concreto, é o de faixas elevadas, tipo quebramolas, localizadas desde a guarita da instituição até a entrada da lanchonete, na metade da parte mais utilizada do estacionamento. Observou-se a presença de trincas na parte superior das faixas, especialmente no encontro da parte superior e da rampa, sendo trincas verticais e horizontais. Além de muitas trincas do tipo couro de jacaré na parte da rampa, quase em sua totalidade. As fissuras existentes nas faixas são mostradas conforme a Figura 6.

Segundo Vieira (2017), em concretos as trincas/fissuras são bastante comuns, havendo, inclusive, fissuras que causam apenas danos estéticos, entretanto as existentes, no encontro da rampa e da parte superior da faixa elevada, não são apenas trincas comuns, pois são em grande quantidade, além de serem bastante largas. Desse modo podem ter sido causadas pela má aderência da parte superior com as rampas.

Já as trincas tipo couro de jacaré das rampas, podem ter sido causadas pelo excesso de peso do tráfego, além do acúmulo de água no período chuvoso, devido à dificuldade de escoamento da água, já que as faixas funcionam como uma barreira para a passagem de água, havendo, portanto, o acúmulo, onde a água infiltra pelas fissuras já existentes e assim podendo aumentá-las. 


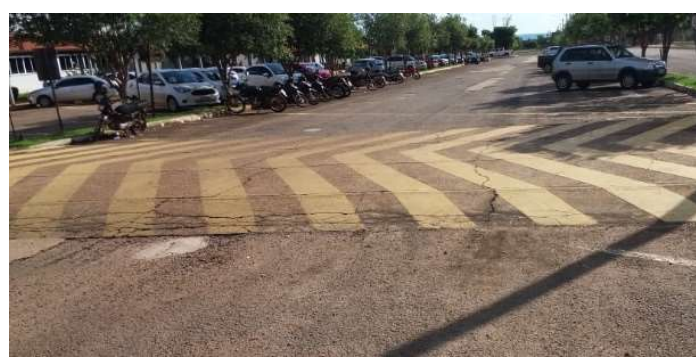

Figura 6: Trincas verticais, horizontais e tipo couro de jacaré nas faixas elevadas.

O desgaste foi observado praticamente em toda a metade do estacionamento, a parte mais utilizada diariamente. Segundo DNIT (2006), o desgaste é caracterizado pela perda/arrancamento progressivo dos agregados e/ou da argamassa fina do revestimento asfáltico, apresentando-se com aspereza superficial, podendo ocorrer em toda a área da superfície. Sendo que este é o caso do estudo em questão, onde o desgaste cobre a grande maioria da metade do estacionamento, conforme as Figuras 7 e 8.

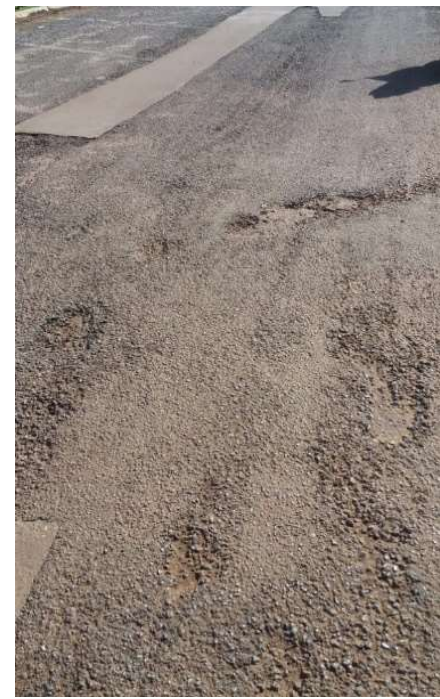

Figura 7: Desgaste cobrindo uma longa faixa do pavimento.

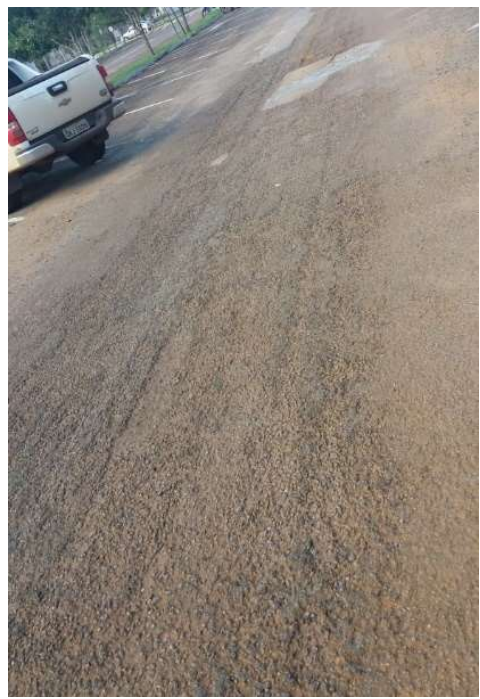

Figura 8: Desgaste cobrindo uma longa faixa do pavimento.

Verificou-se que o desgaste prevalece no meio das vias, onde há tráfego, havendo pouco nas laterais onde os carros são estacionados. Além disso, percebe-se um grande arrancamento dos materiais do pavimento, onde os agregados ficam soltos e dispostos em volta do desgaste, conforme a Figura 9.

Segundo DNIT (2006), o desgaste pode ser provocado pelas seguintes causas: Perda da coesão existente entre o ligante e o agregado, causado pela presença de poeira ou sujeira durante a construção do pavimento; Redução da ligação entre o ligante e o agregado, causado pela oxidação do ligante, pela ação do tráfego e agentes intempéricos; Presença de água no interior do revestimento; Deficiência no ligante asfáltico devido a penetração; e Execução do pavimento em más condições meteorológicas.

Não é possível dizer se o pavimento foi executado em condições meteorológicas desfavoráveis, devido à dificuldade na obtenção desses dados junto à empresa responsável por tal. Pode-se assumir as outras possíveis causas determinadas pelo DNIT, onde o desgaste pode ter sido causado pela ação combinado entre o tráfego e os agentes intempéricos, ou por causa da oxidação do ligante, ou devido à perda de coesão entre o agregado e o ligante, ou até mesmo pela presença de água. 


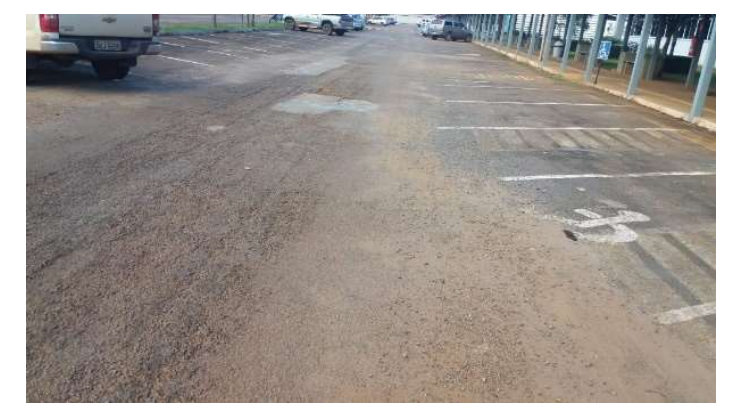

Figura 9: Arrancamento dos agregados do pavimento com desgaste.

Há um acúmulo de água durante o período chuvoso, entretanto isso só ocorre em pontos isolados, especialmente próximo às faixas elevadas. Desse modo é difícil afirmar que esta é uma causa, porém, mesmo que o desgaste seja causado por outros motivos, após sua ocorrência há a infiltração de água no revestimento, visto que este fica desprotegido pela falta de agregado, e isso pode intensificar o desgaste existente.

Não há muitas panelas observadas no pavimento. Foi verificado que estas são reparadas logo que aparecem. Entretanto, as que foram observadas, algumas partem do encontro entre reparos e o pavimento. Outras localizam-se em locais onde há frenagem dos veículos, e, portanto, uma maior concentração de esforços em certos locais, como na entrada da instituição, o qual, na coleta de dados de março, estava em aberto, já em abril foi coberto por material granular, sendo que o mesmo está solto na panela, mas não foi reparado, conforme a Figura 10. Algumas outras panelas foram identificadas, onde a maioria parte do desgaste ou fissuras, conforme é visto na Figura 11.

Foi verificado que novas panelas estão surgindo devido ao desgaste e a falta de aderência entre o pavimento e os reparos de concreto, conforme as Figuras 12 e 13. Por existir longas faixas de desgaste, há o risco do aparecimento de mais panelas, caso não haja reparos, mas, esses reparos, devem ser feitos através da utilização de material asfáltico, de acordo com as normas do DNIT. Pode-se realizar um recapeamento de todo o estacionamento, para cobrir os desgastes que são prevalentes, entretanto, antes do recapeamento, deve ser retirado os reparos com concreto.

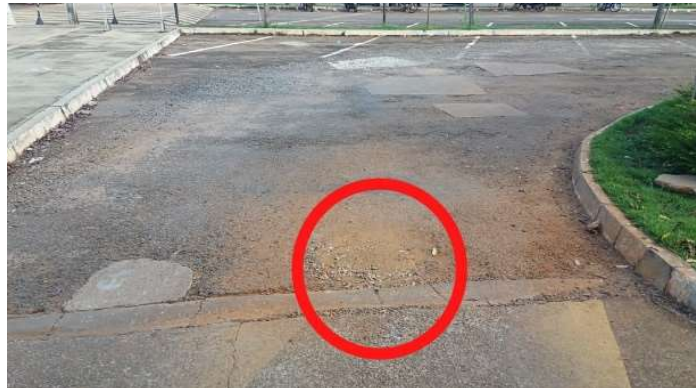

Figura 10: Panela na entrada do ITPAC, preenchida por material granular.

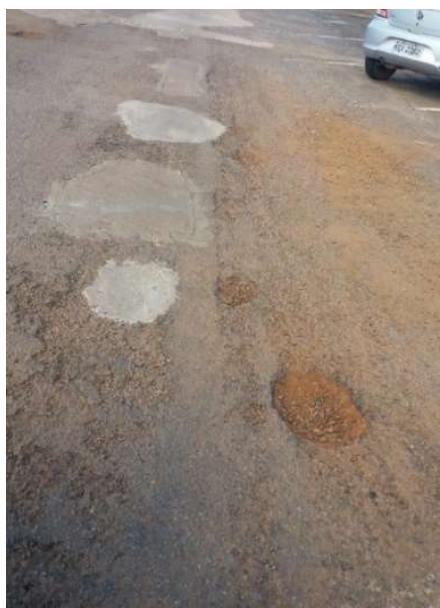

Figura 11: Panela gerada a partir do desgaste. 


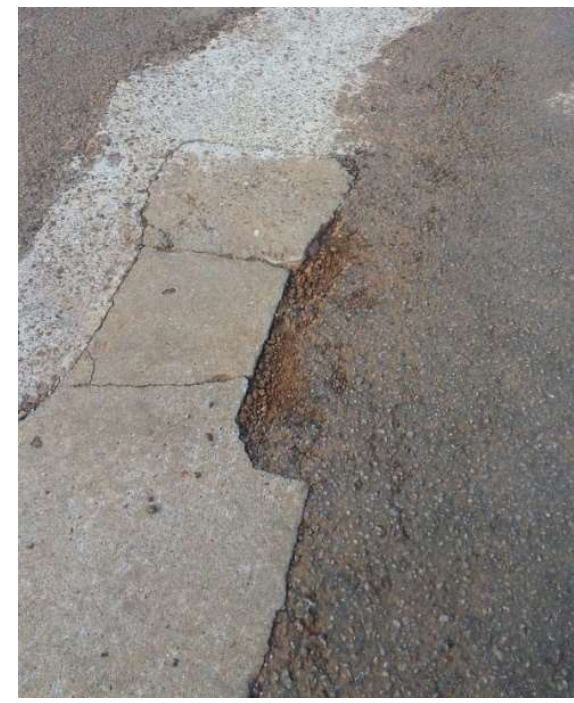

Figura 12: Possível surgimento de uma panela devido à falta de aderência entre o pavimento e o reparo de concreto.

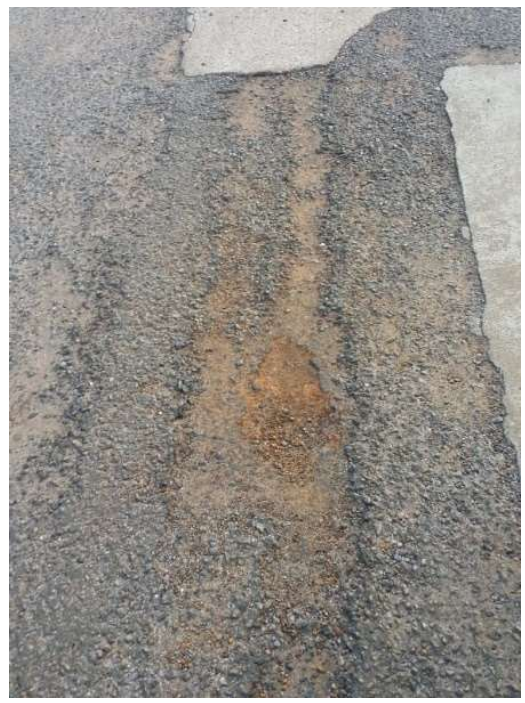

Figura 13: Possível surgimento de uma panela devido à falta de aderência entre o pavimento e o reparo de concreto.

\section{CONCLUSÃO}

Percebe-se que o desgaste é o maior problema enfrentado no pavimento do estacionamento do ITPAC Porto, onde esses evoluem a partir da ação do tráfego e das intempéries, como as chuvas. A partir dessas evoluções, há o aparecimento de panelas, às quais a instituição logo realiza o reparo, mas surge um novo problema, pois o reparo é feito com outro material, o concreto, e não há uma boa aderência com o revestimento asfáltico, o que acaba gerando outras patologias, como trincas e novas panelas.

O atual prédio do ITPAC é relativamente novo, segundo dados do site da instituição, ela foi firmada em Porto Nacional/TO somente em 2008. Considerando a inauguração do estacionamento a partir de 2008, ele tem apenas cerca de 11 anos. Além disso, por se tratar de um estacionamento de uma faculdade, não há tráfego de veículos pesados, desse modo a alta prevalência de patologias é preocupante e deve ser investigada suas causas, a partir de ensaios laboratoriais.

Entretanto, conclui-se que há a necessidade de uma restauração de todo o estacionamento, ou pelo menos da parte afetada, visto que há uma parte substancial do estacionamento que hoje é subutilizada, e dessa forma não apresenta patologias que exigem imediata interferência.

É possível analisar a problemática existente nos reparos do pavimento, onde foram realizados com material incompatível com o material original, utilizando concreto para reparo em um pavimento flexível. Não há uma boa aderência entre os materiais, além da trabalhabilidade dos materiais serem distintas, uma vez que os coeficientes de dilatação térmica dos materiais são distintos. Dessa forma, os reparos de concreto devem ser retirados e novos reparos devem ser realizados, com a utilização de materiais asfálticos adequado, para que não haja o surgimento de trincas entre o reparo e o pavimento, pois as trincas podem evoluir para fissuras e posteriormente para panelas. 
Como o desgaste cobre longas faixas, recomenda-se que seja realizada fresagem de todo o pavimento afetado e seja aplicada uma nova camada de capa asfáltica, respeitando as solicitações causadas pelos veículos em movimento (carregamento dinâmico), e veículos parados (carregamento estático).

\section{REFERÊNCIAS}

ARAÚJO, M. A.. Análise Comparativa de Métodos de Pavimentação: Pavimento Rígido (concreto) x Flexível (asfalto). Revista Científica Multidisciplinar Núcleo Do Conhecimento, v.1, n.11, p.187-196, 2016.

ARTERIS. Remendos em pavimentos. Centro de Desenvolvimento Tecnológico, 2015.

BALBO, J. T.. Pavimentação Asfáltica: materiais, projetos e restauração. São Paulo: Oficina de Textos, 2007.

CNT. Confederação Nacional dos Transportes. Pesquisa CNT de rodovias 2018: relatório gerencial. Brasília: SEST SENAT, 2018.

CNT. Confederação Nacional do Transporte. Rodoviário. 2018.

CNT. Confederação Nacional do Transporte. Transporte rodoviário: desempenho do setor, infraestrutura e investimentos. Brasília, 2017.

COLARES, L. G.. Concessão Administrativa: gerenciando a manutenção de rodovias por parâmetros de desempenho. Brasília: Tribunal de Contas da União, 2011.

DNIT. Departamento Nacional de Infraestrutura de Transportes. Norma DNIT 006/2003-PRO: Avaliação subjetiva da superfície de pavimentos flexíveis e semirrígidos: Procedimento. 2003.
DNIT. Departamento Nacional de Infraestrutura de Transportes. ICM 2018. 2018.

DNIT. Departamento Nacional de Infraestrutura de Transportes. Manual de Restauração de Pavimentos Asfálticos. 2006.

DNIT. Departamento Nacional de Infraestrutura de Transportes. Pavimentos flexíveis: Recuperação de defeitos em pavimentos: especificação de serviço. 2009.

IBGE. Instituto Brasileiro de Geografia e Estatística. Pesquisa Anual de Serviços. 2014.

MARQUES, G. B.. Análise de pavimento flexível: estudo de um trecho crítico na rodovia ERS-421. Lajeado:

Universidade do Vale do Taquari, 2014.

PRODANOV, C. C.; FREITAS, E. C.. Metodologia do trabalho científico: métodos e técnicas da pesquisa e do trabalho científico. 2 ed.. Novo Hamburgo: Universidade Feevale, 2013.

SENÇO, W. Manual de Técnicas de Pavimentação. 2 ed. São Paulo: Pini, 2007

ZANELLA, L. C. H.. Metodologia de Pesquisa. 2 ed. Universidade Federal de Santa Catarina, 2013.

A CBPC - Companhia Brasileira de Produção Científica (CNPJ: 11.221.422/0001-03) detém os direitos materiais desta publicação. Os direitos referem-se à publicação do trabalho em qualquer parte do mundo, incluindo os direitos às renovações, expansões e disseminações da contribuição, bem como outros direitos subsidiários. Todos os trabalhos publicados eletronicamente poderão posteriormente ser publicados em coletâneas impressas sob coordenação da Cognitionis Publishing, da Companhia Brasileira de Produção Científica e seus parceiros autorizados. Os (as) autores (as) preservam os direitos autorais, mas não têm permissão para a publicação da contribuição em outro meio, impresso ou digital, em português ou em tradução. 